\title{
LA DEFINICIÓN LEXICOGRÁFICA DEL CONCEPTO AMERICANISMO LÉXICO EN EL ÁMBITO GERMÁNICO Y ROMÁNICO
}

\author{
ERLA ERLENDSDÓtTIR \\ Universidad de Islandia, Reykjavík \\ erlaerl@hi.is
}

\begin{abstract}
Resumen
En este artículo se estudia la definición lexicográfica del concepto de americanismo en varios diccionarios monolingües y bilingües en el ámbito románico y germánico. En el ámbito hispánico se suele relacionar el término con las lenguas indigenas del continente americano o con el español hablado en Hispanoamérica. En el ámbito anglosajón se define el concepto en relación con el inglés hablado en los Estados Unidos de América. En las demás lenguas románicas y germánicas estudiadas la explicación del concepto tiende a ser o la explicación hispánica o la anglosajona. Así, el uso, la definición y la comprensión del término resultan ser bastante distintos en los dos ámbitos lingüístico-culturales estudiados.
\end{abstract}

PALABRAS CLAVE: americanismo, definición, lexicografía, románica, germánica.

\begin{abstract}
In this article the definition of the concept Americanism in various dictionaries in the Romanic and Germanic fields is discussed. The aim is to point out the difference between the two fields in defining and explaining this concept. In the Hispanic territory the concept americanismo is connected to the Spanish language spoken in Spanish America and in linguistic terms defined eather as a 'word or an expression from Spanish in Latin America' or a 'word from the languages of the aborigenes'. In the English territory, on the other hand, the concept Americanism is always related to the English speaking area of North America and defined as a 'word or phrase peculiar to the English language spoken in the United States'. In other Romanic and Germanic languages the definition tends to be eather the Hispanic one or the English one.

KEY WORDS: Americanism, Lexocography, Definition, Romanic, Germanic.
\end{abstract}

\section{Introducción}

Los lingüistas hispánicos e hispanoamericanos no están de acuerdo a la hora de definir y explicar el concepto de americanismo, lo cual ha dado lugar a una serie de polémicas y de discusiones en torno al tema. Efectivamente, en las últimas décadas han aparecido varias definiciones del término americanismo, así como diversas teorías científicas en las que se manejan definiciones basadas en criterios como el de origen, el de uso o el de difusión geográfica. Lo que tienen en común todas estas teorías y definiciones es el hecho de que relacionan el concepto con el ámbito hispanohablante del continente americano, tal como hace Vaquero de Ramírez (1996: 40) al definir americanismo como "unidad léxica o valor semántico originado en algún país de América", y explicar a continuación que su definición, que está basada en el origen, "intenta acoger tanto los americanismos exclusivos de Hispanoamérica", generales o regionales, "como los que han alcanzado difusión panhispánica". 
Un sesgo hispanocentrista/eurocentrista de este tipo es relativamente frecuente en el estudio del español americano.

Al estudiar las definiciones del concepto americanismo en los diccionarios monolingües españoles de máximo nivel, salta a la vista que, en los artículos consultados, se suele relacionar el vocablo con las lenguas indígenas del continente americano o con el español hablado en Hispanoamérica; por otra parte, en dichos diccionarios, se define la voz angloamericanismo en relación con el inglés hablado en los Estados Unidos de América. Frente a esta tendencia lexicográfica, cuando examinamos las explicaciones que aparecen en los diccionarios de otras lenguas románicas, se evidencia el hecho de que americanismo puede significar — aparte de 'indoamericanismo'- tanto 'angloamericanismo' como 'hispanoamericanismo'.

Ahora bien, ¿cómo es el panorama lexicográfico, en torno a este término, en el ámbito germánico? Nuestro propósito en este trabajo es estudiar las definiciones de la voz en cuestión en los diccionarios monolingües más importantes de las lenguas alemana e inglesa, así como en la lexicografía de los idiomas escandinavos. Se pretende mostrar si la voz americanismo que nos ocupa se usa y se entiende de la misma manera que en el ámbito hispano e hispanoamericano. Después convendrá preguntarse si la definición o la equivalencia termina ofreciendo al usuario de los diccionarios consultados la instrucción de uso más acertada del término estudiado y facilita una comprensión adecuada.

Así pues, hemos creído conveniente empezar con un repaso de las posiciones principales en lo referente a la cuestión de la naturaleza del término americanismo, para luego estudiar la definición que de él se da en el ámbito hispánico y románico. A continuación reseguiremos la explicación de la voz en el mundo germánico, así como su uso, y terminaremos este trabajo con una comparación de la equivalencia del término en los diccionarios bilingües de las lenguas germánicas objeto de estudio en estas páginas.

\section{2. ¿Qué es un americanismo?}

Resulta conveniente empezar por buscar, si no respuestas contundentes y definitivas, sí al menos posibles explicaciones a la pregunta de este epígrafe, así como a otras cuestiones derivadas de ella y casi implícitas: ¿Cómo es entendido y usado el concepto de americanismo en el mundo hispánico? ¿Cómo se registra o se define esta palabra en los diccionarios monolingües españoles? La pretensión de intentar aclarar estas cuestiones deberá tener en cuenta, no obstante, las palabras de Gútemberg Bohórquez (1984: 14), según el cual:

el problema del concepto 'americanismo' en el estudio del español americano, desde el punto de vista léxico y lexicográfico, no ha sido todavía resuelto de modo científicamente satisfactorio.

Por lo que se refiere al término de americanismo, cabe decir que los lingüistas hispánicos e hispanoamericanos han propuesto varias definiciones teóricas del concepto. Sin entrar en una exposición detallada, diremos que la discusión se ha centrado en discernir si americanismo es un término que deba definirse tomando el criterio del uso exclusivo en Hispanoamérica o en cada uno de los países de Hispanoamérica o, por el contrario, si se debe considerar que se trata exclusivamente de voces que tienen su origen en el continente americano. En relación 
con esta dicotomía conceptual y metodológica, resulta útil tener presente que Gútemberg Bohórquez (140), en su obra antes citada, llega a la conclusión de que sólo se puede resolver el problema del concepto de americanismo admitiendo varias posibilidades de definición, es decir: tanto según el criterio de origen, como el de conceptos típicos de Hispanoamérica, y el de uso. Gútemberg Bohórquez (104-106) considera americanismo por origen "todo elemento léxico español de procedencia indígena, o creado por hispanohablantes americanos sobre elementos propios del español general". Conforme a este criterio se puede clasificar los vocablos americanos según la difusión y la procedencia de la voz. El criterio de conceptos típicos de América implica "la expresión o vocablo español que designa conceptos, bien sea de cosas o actividades culturales, o de objetos exclusivos de América y que forman o han formado parte de la vida del hispanoamericano en su desarrollo cultural, aunque esas voces ya sean patrimonio común del español peninsular, o general, por traslado del objeto o la cosa cultural". Y, según Gútemberg Bohórquez, el criterio de uso es la expresión o el vocablo que actualmente es empleado en el español de América, de uso contrastivo o no contrastivo, en relación con el español peninsular. Dado que nuestro objetivo ha sido el de dar una orientación general, remitimos a la obra de Bohórquez para información más detallada sobre este tema en concreto.

A continuación conviene hacer un rápido repaso de las explicaciones que ofrecen varios estudiosos del término objeto de estudio.

Tal como indica Torres Torres (2002: 982), es a mediados del siglo pasado cuando se inicia la discusión acerca del concepto de americanismo dentro del campo de la lingüística hispánica. Sin hacer extensos comentarios podemos agrupar las definiciones, por un lado, en torno al criterio de origen, criterio que Rabanales considera como el único valido para explicar el término de americanismo; y, por el otro, en torno al criterio de difusión geográfica, criterio que defiende, entre otros, Rona. (Gútemberg Bohórquez 1984: 92-93; Torres Torres 2002: 982-983)

Lázaro Carreter (1984: 40) define el concepto americanismo como "palabra de procedencia indígena americana, incorporada a cualquier lengua no americana". Explica (235) que las palabras petaca, cóndor y chocolate son indigenismos en el español en América, pero "con relación al español peninsular, son americanismos". Lázaro Carreter parte del criterio de origen, tanto como Alvar (1990) y Albalá Hernández (2000). Para Alvar, los americanismos léxicos parecen ser los indoamericanismos prehispánicos, pues en su obra Americanismos en la "Historia" de Bernal Díaz del Castillo estudia las voces indígenas que aparecen en la obra de este cronista. Albalá Hernández (2000: 20) delimita el concepto y escribe que entiende por americanismo "toda palabra cuyo étimo inmediato o último pertenezca a una lengua indígena americana precolombina".

Morínigo, en 1996 (XVIII,) distingue, por una parte, entre el concepto indigenismo, que son "las voces indígenas incorporadas firmemente al español general o regional, ya sea en su forma etimológica o adaptada a la fonología o morfología españolas" y, por la otra, el término americanismo, vocablo que explica como "las palabras creadas o inventadas en América o derivadas de otras palabras españolas patrimoniales, según las normas de la fonologia española, para designar seres, objetos o instituciones propios de la naturaleza, cultura y vida americanas". Y en el Diccionario del español de América (1996: XXIII) y el Nuevo diccionario de americanismos e indigenismos (1998: 10) incluye también palabras españolas de acepciones diferentes de las tradicionales en España, arcaísmos, marinerismos 
y regionalismos españoles que hoy se desconocen en la Península. A lo enumerado habrá que añadir latinismos, galicismos, anglicismos, africanismos, etcétera, voces que han llegado a formar parte del léxico del español americano.

Buesa Oliver y Enguita Utrilla (1992: 24) sintetizan la idea que Haensch y Werner tienen del concepto como "todo elemento léxico que se difiere de su empleo en la norma peninsular, bien porque no sea conocido en España y su uso esté, por lo tanto, restringido al territorio americano [...], bien porque se emplee en América con acepciones diferentes o adicionales a las que tiene en la Península, o bien porque ofrezca alguna diferencia de tipo gramatical, $[. .$.$] ". Esto es, el criterio de uso y contrastivo.$

Steel (1990: 14-15) declara que ha ampliado el ámbito "más allá de lo que se considera normalmente como americanismo" e incluye varias categorías de palabras como son los "americanismos de frecuencia", esto es, "términos que, aunque no desconocidos en España [...], son reconocida y característicamente «americanos» a causa de su altísima frecuencia de uso en Latinoamérica (o partes de ella)" y "americanismos sintácticos y morfológicos", refiriéndose a "ciertos sufijos y palabras características formadas con ellos". Además explica que los "otros americanismos (o argentinismos, chilenismos, mexicanismos, etc.)" encierran "neologismos o palabras de origen hispanoamericano" y las voces del español peninsular obsoletas, arcaicas o únicamente de empleo dialectal cuyo subgrupo son palabras "originalmente restringidas a la jerga de la navegación española".

Valga lo expuesto para reflejar la heterogeneidad en la definición del concepto, pues como queda dicho se han aplicado diferentes definiciones al concepto americanismo en el campo lingüístico hispánico, cabe destacar, no obstante, que todas las definiciones propuestas suelen relacionarlo con el ámbito hispánico, hecho que es, desde el punto de vista de la lingüística hispánica, quizá lógico, puesto que dentro de este campo científico no hay peligro de que surjan confusiones.

\section{La definición de americanismo en español}

Cuando se consultan los diccionarios monolingües españoles para averiguar si se registra el vocablo americanismo y para estudiar su definición, se observa que en general la voz y el concepto lingüistico son relacionados casi exclusivamente con Hispanoamérica.

Casares (1984: 46) define la voz como "vocablo o giro propio de los americanos que hablan español'. Por otra parte, puede llamar la atención que americano es 'natural de América' y que americanista quiere decir 'persona que estudia lo relativo a América'. El primer vocablo, americanismo, hace referencia a un territorio más reducido (Hispanoamérica), mientras que los dos últimos citados, aluden a todo el continente americano.

En el diccionario de María Moliner (Diccionario del uso del español, 1966: 163), el artículo de la voz aquí objeto de estudio tiene dos acepciones, la segunda de las cuales es la que nos interesa: 'expresión añadida al español en los pueblos americanos de habla española'. Comprendemos, por tanto, que el término es definido simplemente como hispanoamericanismo. Al consultar la voz americanista, hallamos que se trata de "una persona que estudia las lenguas, historia o antigüedades de la América española' mientras que americano designa a 'una persona de América'. El término de angloamericanismo no consta en el diccionario, pero el concepto de hispanoamericanismo, por otro lado, sí ha sido registrado (59): 
[1) Espíritu de solidaridad, y de tendencia a fomentarlo, entre los pueblos americanos de origen español, entre sí y con España.] 2) *Expresión propia de algún país hispanoamericano incorporada al español hablado en él.

No descartamos la posibilidad de que la segunda acepción del artículo citado tenga el mismo significado que indoamericanismo (prehispánico), un término que no ha sido incorporado a esta primera edición del diccionario de María Moliner.

La consulta de la edición de 1998 del Diccionario del uso del español (163) nos permite confirmar que ha habido un cambio en la formulación de la definición del concepto de americanismo, pero el sentido es el mismo. El concepto se define ahora como:

Palabra o expresión originaria de la América de habla española y utilizada en otras áreas del español o en otras lenguas.

Lo cual significaría 'indoamericanismo prehispánico'; y la subacepción es 'palabra o expresión propia del español de América', es decir, 'hispanoamericanismo'. La voz americanista tiene el arriba comentado significado, mientras que americano se explica así: 'de América $\Rightarrow$ Amerindio, centroamericano, criollo, esquimal, gaucho, hispanoamericano, indiano, *indio, norteamericano, yanqui', o sea, 'una persona de América'. La segunda acepción, 'de los Estados Unidos', es marcada de informal. Del concepto angloamericano, que ha tenido entrada en el diccionario, se indica: 'por oposición a «hispanoamericano», de la América de habla inglesa' (182). La voz angloamericanismo no consta en el diccionario, ni tampoco indoamericanismo.

El concepto de hispanoamericanismo aparece, por otra parte, con una segunda acepción, la cual es:

Palabra o expresión originaria de la América de habla española y utilizada en otras áreas del español o en otras lenguas = Americanismo (1491).

y cuya subacepción es 'palabra o expresión propia del español de América = Americanismo'. La información que ofrece el artículo es la que hispanoamericanismo, que parece significar tanto indoamericanismo como hispanoamericanismo, es sinónimo a americanismo. Salta a la vista que las acepciones no-se diferencian en nada.

El Diccionario de la Real Academia Española (DRAE, 2001) ofrece varias explicaciones concernientes a la voz americanismo; de las acepciones de su artículo son la quinta, la sexta y la séptima las que nos interesan y las que a continuación reproducimos:

5. Vocablo, giro, rasgo fonético, gramatical o semántico que pertenece a alguna lengua indígena de América o proviene de ella (2001: 136).

La alusión 'alguna lengua indígena de América' debe remitir a todo el continente, al norte y al sur. No cabe la menor duda, pues, de que el artículo del $D R A E$ en esta acepción se refiere a los indoamericanismos.

Sin embargo, en la acepción que sigue:

6. Vocablo, giro, rasgo fonético, gramatical o semántico peculiar o procedente del español hablado en algún país de América (2001: 136). 
Aparece una definición que corresponde en definitiva a hispanoamericanismo en oposición a angloamericanismo. La séptima acepción del artículo, y la última que comentamos aquí, es:

\section{7. angloamericanismo (2001: 136)}

El término al que se nos remite es definido en el propio DRAE como:

Vocablo, giro o rasgo idiomático peculiar o procedente del inglés hablado en los Estados Unidos de América (2001: 155).

Hay que destacar que el Diccionario de la Real Academia Española da la definición más completa del término americanismo, sobre todo gracias a la incorporación de la última acepción, que, por otra parte, no aparece en ningún otro diccionario consultado. Finalmente conviene indicar que en el Diccionario de la Academia no se registra hispanoamericanismo con el significado metalingüístico que venimos comentando, sino como:

Doctrina que tiende a la unión espiritual de todos los pueblos hispanoamericanos (2001: 1219)

Una simple ojeada a los artículos del Diccionario ilustrado de la lengua española (DGILE) basta para darse cuenta de que las definiciones de los vocablos comentados no difieren en nada de las análogas del DRAE, de cuya entrada americanismo proceden. El concepto angloamericanismo no ha sido incorporado al diccionario ni tampoco se encuentra incluida en él la voz indoamericanismo.

En el diccionario Clave (1996: 86) se explica americanismo en términos lingüísticos como:

palabra, significado o construcción sintáctica de alguna lengua indígena americana o del español de algún país americano, esp. los empleados en otra lengua: Las palabras 'patata','cacao' y 'cacique' son americanismos.

Puede observarse en este caso una definición en consonancia con las acepciones ya estudiadas del DRAE. El artículo nos informa, en pocas palabras, de que la voz comprende, en primer lugar, a 'indoamericanismo (prehispánico)' y, en segundo lugar, a 'hispanoamericanismo'. Es una definición más bien hispanocéntrica /eurocéntrica igual que la del Diccionario Salamanca de la lengua española (1996: 82):

1. Palabra o expresión propia de los hispanoamericanos o procedente de alguna lengua indígena de Am. 2. (no contable) Carácter o condición de americano. 3. (no contable) Estudio y afición por todas las cosas americanas.

Cuando buscamos la definición de la forma léxica americano en el diccionario Salamanca, leemos que se trata de 'una persona', en primer lugar, 'de América', y en segundo lugar, 'de los Estados Unidos'. En el diccionario Clave (1996: 86) se define este vocablo de modo semejante, pero resulta interesante reseñar el siguiente comentario dada la divergencia que 
presenta, respecto a la definición del diccionario Salamanca, en la restricción que plantea a la aplicación del término:

SEM. En la acepción 1 [De América (uno de los cinco continentes) o relacionado con ella (...)], no debe emplearse con el significado de 'estadounidense': Los \{*americanos $>$ 'estadounidense'? viven mayoritariamente en ciudades.

El concepto angloamericano, o angloamericanismo, no queda registrado en el diccionario Salamanca, ni tampoco en el Clave.

\section{La definición de americanismo en el ámbito románico}

El propósito de este apartado es ofrecer una pequeña muestra del tratamiento lexicográfico que el concepto objeto de nuestro estudio recibe en otras lenguas románicas, en concreto en diccionarios del francés, del italiano y del portugués. Se trata de observar si las definiciones del término lo relacionan con el mundo hispanoamericano o más bien con el angloamericano.

\subsection{El francés: americanisme}

El diccionario histórico de la lengua francesa, Robert (1992: 61, 1998: 110), define americanisme como 'admiration pour l'Amerique' y la voz americaniste 'peuvent en revanche s'appliquer au continent entier et notamment aux études indiennes et «précolombiennes»', mientras que el adjetivo americain ha adquirido el significado restringido de 'de los Estados Unidos':

Cependant, aprés l'Indépendance des Etats-Unis, le mot, d'abord comme nom (17831784), puis comme adjectif, s'applique á ce pays seul.

Hoy en día ese es el uso común del vocablo americano, no solamente en el francés, sino en las diversas lenguas europeas como veremos más adelante.

El diccionario Le Grand Robert de la Langue Française (Robert, 2001: 440) registra el término americanisme con tres significados, son dos los que aquí interesan; el primero, que es semejante a la antes citada acepción del diccionario histórico, es: 'admiration, imitation du mode de vie, de la civilisation des États-Unis'; el segundo, en términos lingüísticos, es: 'idiotisme américain (par rapport à l'anglais)' y el ejemplo que aporta la acepción es "les américanismes et les briticismes* d'un dictionnaire anglais", y a continuación se explica que también significa 'emprunt (du française, etc.) à l'anglais des États-Unis: Stock-car est un américanisme (en français)'.

Finalmente queremos citar el Trésor de la langue française (http://www.tlf.fr), según cuya acepción americanisme es 'idiotisme propre au parler anglais d'Amérique du Nord'.

Podemos afirmar, sin lugar a dudas, que el concepto estudiado quiere decir angloamericanismo en los dos casos mencionados. Cabe mencionar que llama la atención que la definición en términos lingüísticos no aparece en los diccionarios franceses consultados hasta en las últimas ediciones. Nos referimos sobre todo al diccionario Robert. 


\subsection{Italiano: americanismo}

Como vemos por la siguiente cita del diccionario Vocabolario della lingua Italiana (Istituto della Enciclopedia Italiana, 1986: 151) americano refiere a 'estadounidense':

b. Nel linguaggio corrente, è più comunem. riferito agli Stati Uniti d'America; gli Americani, gli Statunitensi.

Si bien es cierto que en sentido amplio también se refiere a 'Dell'America'.

Por lo que respecta al artículo del concepto americanismo hallamos explicaciones semejantes a las de otros diccionarios consultados:

a. Parola o locuzione propia di una delle lingue parlate nel continente americano che sia usata nella nostra lingua $o$ in altre lingue europee -nella forma originaria o adattata- in partic., i termini statunitensi introdottisi in Europa in siguito all'intervento degli Stati Uniti nella segonda guerra mondiale. Storicamente, si definisano anche americanismi i termini entrasi nelle lingue europee (prima lo spagnolo, poi il portoghese, più tarde il francese, l'inglese e, indirettamente, l'italiano) dalle lingue indigene dell'America [...] (1986: 151)

En la acepción encontramos, de hecho, dos explicaciones: en primer lugar se define el término como "voz o giro procedente de una de las lenguas habladas en el continente americano', pero se pone énfasis en el hecho de que se trata sobre todo de un elemento léxico de los Estados Unidos —es de suponer, pues, del inglés. En la segunda parte de la acepción se refiere a que históricamente americanismo se aplica a términos o voces procedentes de las lenguas indígenas de América - es decir, a indoamericanismos - que penetraron en las lenguas europeas: primero en el español, luego en el portugués, y más tarde en el francés, en el inglés e, indirectamente, en el italiano.

La acepción b.:

b. Termini peculiare alla lingua inglese che si parla negli Stati Uniti, o allo spagnolo dell'America centro meridionale.

nos informa que la palabra se puede aplicar con el significado o de angloamericanismo o de hispanoamericanismo.

Ahora convendría averiguar si en los diccionarios italianos de publicación reciente ha cambiado en algo la definición del concepto que nos interesa. En el Garzanti I Grandi Dizionari Italiano (2000: 90) el concepto de americanismo se define en términos lingüísticos como 'parola o espressione propria dell'inglese parlato negli Stati Uniti d'America o delle lingue iberiche dell'America centromeridionale', acepción que quiere decir que se trata de angloamericanismo y de iberoamericanismo. El concepto iberoamericanismo se refiere probablemente a voces tanto del español americano como del portugués americano, o sea hispanoamericanismo y lusoamericanismo. El término también significa 'parola o espressione originaria delle lingue indiane d'America entrata in un'altra lingua', lo cual sería, entonces, indoamericanismo.

La definición del diccionario De Mauro (2000: 97) no difiere en mucho de la que acabamos de comentar, pues señala que americanismo es "parola o espressione propria delle 
lingue parlate nel continente americano, spec. dell'inglese degli Stati Uniti d'America, entrata in un'altra lingua (per es. jazz, jeans, ananas nell'italiano)', o sea, que debe tratarse de préstamos procedentes de cualquiera de las lenguas habladas en el continente americano e incorporado a otra lengua. Habrá que hacer hincapié en el hecho de que se trata sobre todo de angloamericanismos. Y análoga es la definición del Vocabolario della lingua italiana de Zingarelli (2002: 82), donde leemos que americanismo es 'parola o forma propria dell'uso americano, spec. nordamericano'.

\subsection{Portugués: americanismo}

La definición de americanismo en el Dicionário da Lingua Portuguesa de Porto (1977) no añade nada nuevo a nuestro estudio, pues señala que se trata de 'predileç̧ão pelas coisas da América' y americano es 'natural ou habitante da América'. Se trata ésta de una definición neutral, pues alude a todos los países del continente americano.

En el Grande Dicionário da Língua Portuguesa (Machado, 1981: 403) interesa la segunda acepción que entra en el terreno lingüístico: 'palavra ou frase da língua inglesa que só é usada na América do Norte ou nela teve origem'; debe tratarse del concepto de angloamericanismo. En la misma obra lexicográfica americano se define como 'indivíduo natural da América' y 'cidadão dos Estados Unidos da América do Norte, norteamericano'. Salta a la vista que norteamericano no incluye a los canadienses ni a los mexicanos que, geográficamente, se encuentran en América del Norte.

La obra lexicográfica Grande Dicionário da Língua Portuguesa (Cândido de Figueiredo, 1996: 163) ofrece las siguientes explicaciones del concepto de americanismo: la primera acepción es 'admiração pelas coisas da América, especialmente dos Estados Unidos' y la segunda 'palavra, locução, construção que se formou e se usa nas línguas europeas faladas na América'. La segunda acepción llama la atención porque aquí americanismo aparece como hiperónimo de angloamericanismo, hispanoamericanismo, lusoamericanismo y galoamericanismo, o sea voz formada en una de las lenguas europeas habladas en América, pero no es voz de las lenguas amerindias, o sea indoamericanismo.

Conviene también citar el diccionario de la Academia de las Ciencias de Lisboa, Dicionário da Lingua Portuguesa Contemporânea (2001: 213). Según éste americanismo es:

1. Concepção ou estilo de vida, mentalidade, costumes peculiares aos povos da América, sobretudo ao dos Estados Unidos da América [...] 2. Admiração ou predileç̧ão pelas coisas, pelo modo de vida, pela civilização americana, sobretudo pela dos Estados Unidos da América [...] 3. Palavra, expressão ou modo de pronunciar próprio das pessoas naturais dos Estados Unidos da América (por oposição aos ingleses). [...].

El concepto se relaciona, sobre todo, con los Estados Unidos tal como expresa la cita. Sorprende, sin embargo, el hecho de que en el campo lingüístico sólo se refiere al inglés americano y no a las demás lenguas del continente.

La explicación del Novo Dicionário da Lingua Portuguesa (Nova Fronteira, 1975: 84) nos interesa por la siguiente acepción:

5. Particularidade do inglês falado nos E.U., espanhol da América, ou do português do Brasil [Nesta acepç., cf. brasileirismo (2).]. 
Esta definición evidencia un punto de vista metalexicográfico y una ideología lingüística claramente eurocentrista (tanto para el ámbito hispano, como para el anglosajón), aspecto comentado ya en diversos puntos del recorrido que venimos realizando en estas páginas. Además el artículo del Novo Dicionário nos recuerda la existencia de la lengua portuguesa en el continente americano - lo cual, por otra parte, debe hacernos pensar en otras "lenguas americanas", como por ejemplo el francés hablado por miles de canadienses. A pesar de ello, lo cierto es que la primera acepción del término que recoge el diccionario portugués consultado no es otra que: 'Admiração, apreço [...] das coisas da América, particularmente dos E.U'.

En suma, podemos afirmar a modo de primera conclusión que en el mundo románico el concepto americanismo no se relaciona necesariamente con Hispanoamérica, sino más bien con los Estados Unidos de América y la lengua inglesa, y ello es debido con seguridad a la importancia política, económica y cultural de este país en el mundo a lo largo del siglo pasado.

\section{La definición de americanismo en el ámbito germánico}

Ahora conviene estudiar la definición del concepto en cuestión en las lenguas germánicas: el inglés, el alemán y las lenguas escandinavas (danés, noruego y sueco). No estudiaremos aquí la definición en la lengua holandesa, cuyo término, por cierto, es amerikanisme; tampoco en el islandés, puesto que el término no existe en esta lengua nórdica'.

\subsection{El inglés: Americanism}

Según el diccionario Oxford English Dictionary (OED) (1989: 398), fue el estudioso J. Witherspoon quien usó y explicó el término americanism por primera vez, en 1781. Efectivamente, este autor define y acuña el concepto con las siguientes palabras:

[...] Americanisms, by which I understand an use of phrases or terms, or a construction of sentences, even among persons of rank and education, different from the use of the same terms and phrases, or the construction of similar sentences, in Great Britain. The word Americanism, which I have coined for the purpose, is exactly similar in its formation and signification to the word Scotticism.

Esta primera aparición del término en el mundo anglosajón pretende referir, sin lugar a dudas, la diferencia en el uso del inglés en los Estados Unidos de América y en Gran Bretaña, en Europa. Ahora bien, más allá del valor histórico de esta definición, y por lo que respecta a la explicación del término en el diccionario $O E D$ (1989: 398), nos interesa la tercera acepción del vocablo:

A word or phrase peculiar to, or extending from, the United States. ${ }^{2}$

1 En el islandés, la voz Ameríka, 'América', puede significar todo el 'continente americano, así como los 'Estados Unidos de América'. Amerikumað̋r quiere decir 'persona de América' y 'estadounidense'; el acortamiento $k a n i$ es una forma peyorativa para designar a un estadounidense.

2 Las otras acepciones son: "1. Attachement to, or political sympathy with, the United States" y "Any thing peculiar to, or characteristic of, the United States". 
Se ofrece aquí la acepción más común del vocablo en la lengua inglesa, en la que se interpreta el 'procedente de los Estados Unidos' como referencia inequívoca al inglés americano. Resulta interesante constatar que esta definición se asemeja a la propuesta en el DRAE (1992: 101, 2001: 155) para el elemento léxico angloamericanismo, que es como sigue:

Vocablo, giro o rasgo idiomático peculiar o procedente del inglés hablado en los Estados Unidos de América.

La consulta al diccionario Webster's Third (1961: 68) muestra que en esta obra la primera acepción de la voz americanismo es precisamente la referente al campo lingüístico:

1: a characteristic feature of American English esp. as contrasted with British English $[\ldots]$.

En ella se recoge, por lo tanto, la definición que plantea dicho término como 'peculiaridad' del inglés americano en contraste con el inglés europeo. La explicación que da el The Random House Dictionary of the English Language (1983: 66) del término estudiado es parecida a lo comentado, esto es, 'a word, phrase, or other language feature that is especially characteristic of the English language as spoken in the U.S.', y una acepción similar aparece en el Collins English Dictionary (1994: 48): 'a costum, linguistic usage, or other feature peculiar to or characteristic of the United States, its people, or their culture'. En consonancia con lo comentado aparece la explicación de Mathews (1956: V) en el prólogo a la obra $A$ Dictionary of Americanisms. On Historical Principles. Ahí dice que "as used in the title of this work, "Americanism" means a word or expression that originated in the United States" y a continuación enumera algunos ejemplos: "the term includes; outright coinages, as appendicitis, hydrant, tularemia; such words as adobe, campus, gorilla, which first became English in the United States; and terms such as faculty, fraternity, refrigerator, when used in senses first given them in American usage."

Por lo que se refiere a otras acepciones de la voz, acepciones que aparecen posteriores a la de 'característica lingüística' ya comentada, cabe decir que las explicaciones que dan los dos diccionarios de la lengua inglesa -el OED, el Webster's Third, el The Random House Dictionary of the English Language y el Collins English Dictionary- coinciden en relacionar el concepto con los Estados Unidos de América, tanto si se recoge como 'peculiaridad o una característica cultural, política o ideológica' de dicho país, como cuando es definido en el sentido de 'interés o la afición al estudio de las tradiciones' de aquel territorio. El término Anglo-American significa 'un americano de origen inglés', Anglo-americanism, que parece ser de uso reducido, equivale a 'vulgarismo' (OED 1989: 466; Webster's Third 1989: 58). Cabe señalar que el término hispanoamericanism no figura en dichos diccionarios.

Resulta interesante cotejar estos datos de la lengua inglesa en sus diccionarios con otros obtenidos de obras ya no estrictamente lexicográficas aunque sí del ámbito de la lexicología. Así por ejemplo, Shaw Fairman - en su estudio sobre los préstamos de procedencia hispánica e hispanoamericana en el inglés (1987/1988: 305-327) - suele hablar de las palabras o de las voces "del Nuevo Mundo". Este autor no utiliza ningún término específico para referirse a las voces procedentes de los países hispanoamericanos y nunca aparece la voz americanismo a lo largo de su estudio. Se trata de una opción terminológica que alinea a 
este autor con los estudiosos del campo en cuestión en Alemania, tal como veremos en el siguiente apartado.

\subsection{El alemán: Amerikanismus}

Desde principios del siglo pasado varios estudiosos alemanes se han ocupado en profundidad del tema de la penetración de los préstamos de origen indoamericano en la lengua alemana. El resultado de la investigación de los distintos eruditos en este campo científico ha sido publicado en varias ocasiones; aquí nos va a interesar ahora, sobre todo, el título de estos estudios.

Lokotsch (1926) usa la denominación Etymologisches Wörterbuch der amerikanischen (indianischen) Wörter im deutschen, o sea 'Diccionario etimológico de las voces americanas (indígenas) en el alemán', obra que recoge palabras procedentes de las distintas lenguas indígenas de todo el continente.

El estudioso Palmer (1939) titula su obra Neuweltwörter im Deutschen, 'Palabras procedentes del Nuevo Mundo en el alemán', e incorpora voces de todos los países del continente americano, sean de origen inđígena o sean de las lenguas de cultura del Viejo Mundo.

Friederici (1960) por último titula su obra Amerikanistisches Wörterbuch und Hilfswörterbuch für den Amerikanisten, lo que quiere decir 'Diccionario americano y diccionario de apoyo para los americanistas'. Con esta denominación el autor quiere implicar, sobre todo, a las lenguas autóctonas del continente americano, tanto del norte como del sur, pero en su obra registra palabras procedentes tanto del quechua o del guaraní, etc., como del algonquin o el iroquín, etc. - lenguas habladas por los indígenas de América del Norte--, así como creaciones nuevas o palabras derivadas de palabras patrimoniales del español, del inglés, del francés o del portugués. ${ }^{3}$

Ninguno de los tres autores citados usa el término americanismo, ni en el sentido de 'hispanoamericanismo' o 'angloamericanismo', ni tampoco en el sentido de 'voz procedente de las lenguas autóctonas de América', es decir, 'indoamericanismo'. No aparece el concepto Amerikanismus a lo largo de sus obras; ello se debe probablemente al hecho de que el término tiene otro significado en la lengua alemana, como veremos a continuación.

En efecto, comprobemos la definición del vocablo en algunos diccionarios monolingües alemanes. En el diccionario Duden (1999: 186) se informa, en el artículo de la entrada Amerikanismus, de que se trata de un término que pertenece al campo de la lingüística (Sprachwissenschaft). La primera definición es: 'Sprachliche Besonderheit des amerikanischen Englisch', es decir, 'característica lingüística del inglés americano'. La segunda acepción identifica el término con 'Entlehnung aus dem Amerikanishcen [ins Deutsche]', que quiere decir 'préstamo del americano en el alemán'. Aquí el ambiguo 'americano', o Amerikanisch, debería entenderse designando a todas las lenguas habladas en dicho continente, pero no es así, ya que significa 'das amerikanische Englisch', o sea, 'angloamericano' o 'el inglés americano'.

3 Aquí ofrecemos unos ejemplos del Diccionario de Friederici: angloamericanismos: hummock, interval y leggings; hispanoamericanismos: isleño, melera y mochilera; galoamericanismos: mapou, mangeur de lard; lusoamericanismos: milho, manão; indoamericanismos prehispánicos: canoa, quillaya y guano, y indoamericanismos preanglosajones: moose, maskinong y pemmican. 
El segundo diccionario monolingüe alemán consultado Brockhaus Wahrig (1980: 192) explica la voz americanismo (Amerikanismus) de modo semejante a como lo hace el antes citado Duden; de manera que el término lingüístico sólo hace referencia al inglés hablado en los Estados Unidos de América, como se ve por la siguiente cita:

\begin{abstract}
Amerikanismus (m.; -, -men) 1 (Sprachw.) Eigentümlichkeit des amerikanischen Englisch 1.1 dem amerikanischen Englisch nachgebildete Spracheigentümlichkeit in einer anderen Sprache 2 Eigenart der Bevölkerung der USA in Geisteshaltung, Lebensstil, Kultur- u. Wirtschaftsformen.
\end{abstract}

La primera acepción del artículo, que tiene que ver con la lingüística, informa, en primer lugar, de que se trata de 'una peculiaridad del inglés americano'; en segundo lugar se explica como 'un elemento léxico prestado de esta lengua a otras'. Y la segunda acepción define Amerikanismus como 'una característica de la nación estadounidense en cuanto a estilo de vida, cultura y economía'. Cabe decir que la consulta del diccionairo Deutsches Wörterbuch (Wahrig, 1986: 157) ofrece una definición parecida a la que acabamos de comentar.

Una vez más podemos comprobar que el concepto americanismo sólo hace referencia a la lengua mayoritaria en el norte del continente americano, es decir, en los Estados Unidos, y nunca se relaciona con Hispanoamérica. Para referirse a la parte central o el sur del continente americano, se suele usar Mittelamerika o Südamerika, 'Centroamérica' y 'Sudamérica', respectivamente, o el compuesto América Latina, Lateinamerika.

Antes de pasar a estudiar el término en los diccionarios de las lenguas escandinavas, conviene mencionar que en Duden (1999: 1831) figura la entrada Hispanoamerikanismus, término que se aplica a 'pecularidad lingüística del español hablado en América Latina'; y también, Hispanoamerikaner, 'hispanoamericano'.

\title{
6.3. Las lenguas escandinavas
}

En lo referente al estudio de la definición del concepto americanismo en las lenguas escandinavas, la conclusión a la que habremos de llegar es similar a lo recapitulado en la sección dedicada a las otras lenguas germánicas estudiadas; esto es: se suele usar el vocablo sobre todo para los elementos léxicos procedentes del componente angloamericano, o para dar nombre a la influencia lingüística del inglés americano. En estas lenguas escandinavas, tal como sucede en el alemán, se distingue la zona anglosajona de la zona hispana del continente, por cuanto se utiliza el compuesto sustantivo Latinamerika, 'América Latina', o Sydamerika, 'Sudamérica', así como el adjetivo latinamerikansk, 'latinoamericano', o sydamerikansk, 'sudamericano'.

\subsubsection{El danés: amerikanisme}

Empecemos con el danés, en cuyo diccionario Ordbog over de danske sprog (Det danske sprog og litteraturselskab, 1975: 517) se explica la entrada de amerikanisme como:

[...] hvad der er ejendommeligt for Amerika og Amerikanerne $\|[\ldots]$ især (sprogv.) om ejend.heder ved det engelske sprog i Nordam. 
[...] lo caracteristico de América y los americanos // sobre todo (ling.) lo que es peculiar del inglés en América del Norte.

En el diccionario Nudansk ordbog (Politikens forlag, 1986: 48), por otra parte, la definición resulta más imprecisa: 'sproglig vending der er ejendommelig for amerikansk, overført til andre sprog', lo cual quiere decir 'voz o giro idiomático peculiar del americano en otras lenguas'. De esta definición podriamos deducir que se esté refiriendo a la influencia de todas las lenguas existentes de América. Cabe entonces preguntar cómo se explica o se define el término amerikansk, 'americano', en el diccionario danés. La información encontrada no aporta datos nuevos; en realidad sólo encontramos distinto la indicación de la categoría gramatical, adj. 'adjetivo'. En el diccionario Nudansk med etymologi (Politikens forlag, 2000: 61) se define el término más precisamente como:

1. et sprogligt træk el. en vending som er karakteristisk for den nordamerikanske variant af engelsk, og som optræder $i$ et andet sprog.

1. rasgo o giro idiomático peculiar del inglés hablado en Norteamérica incorporado a otra lengua.

En la misma obra, la primera acepción del adjetivo amerikansk, 'americano', designa a 'algo relacionado con los Estados Unidos', y la segunda, 'algo relacionado con Norteamérica y Sudamérica'; mientras que el sustantivo amerikaner, 'persona americana', significa 'estadounidense'.

El diccionario Den danske ordbog (Gyldendal, 2003: 166) del Instituto Lexicográfico Danés explica el término americanismo como

1 det karakteristiske ved kulturen og livsstilen i USA; [...] 2 (spr.) amerikansk ord el. udtryk i et andet sprog.

La primera acepción quiere decir 'lo característico de la cultura y del estilo de vida en los Estados Unidos', y la segunda, que tiene que ver con la lingüística, es 'una palabra o un giro americano que ha tenido entrada en otra lengua'. Esta última definición se puede interpretar de tal manera que podría aplicarse a una voz tomada en préstamo de una de las lenguas habladas en el continente americano. No obstante, la explicación de amerikansk en este diccionario nos hace dudar de que así pueda ser, pues la primera acepción es, en primer lugar, 'lo relacionado con los Estados Unidos y característico de ese país y de sus habitantes' y, en segundo lugar, 'el inglés hablado en Norteamérica, sobre todo en los Estados Unidos'. La segunda acepción dice que se trata de algo 'de Norteamérica o relacionado con ese territorio, Centroamérica y Sudamérica'.

\subsubsection{El noruego: amerikanisme}

La definición noruega del concepto objeto de estudio no difiere en mucho de la danesa, ya que el diccionario del noruego, Norsk ordbok (Norske samlaget, 1966: 69), ofrece la siguiente explicación: 
Noko som er sermerkt for Amerika eller amerikanerne; amerikansk ord el serdrag i europeiske mål (i Amerika), serl. eng.

Algo que es característico o peculiar de América y de los americanos; palabra americana o rasgo peculiar en América, sobre todo del inglés, presente en las lenguas europeas.

Por la definición vemos que el amerikanisme en noruego se relaciona especialmente con el inglés del continente americano. Esta univocidad se ve no solo confirmada en otra obra destacable, el diccionario Bokmålsordboka (1997: 11), sino que en este trabajo lexicográfico se afirma que el término sólo se relaciona con los Estados Unidos:

1 egenskap, særtrekk, f eks i språk, mote, smak som skyldes påvirkning fra USA 2 språkv: særtrekk ved det engelske språket i USA.

Es decir, 'característica o rasgo, por ejemplo, en la lengua, en la moda y en el gusto debido a la influencia de los Estados Unidos' y, en términos lingüísticos, 'pecularidad del inglés americano'. La definición del diccionario Nynorskordboka (Norske samlaget, 2001: 12) es análoga a la comentada ${ }^{4}$.

\subsubsection{El sueco: amerikanism}

Nos ocupamos finalmente del sueco. Al consultar el diccionario monolingüe de la Real Academia Sueca (Svenka akademien, 1989: A1193), nos hallamos ante una definición muy parecida a las de otros diccionarios escandinavos:

3) språkv. för Amerika egendomligt uttryck i där taladt språk från annan världsdel; särsk. om uttryck, som äro egendomliga för det engelska språket i Nordamerika.

[...] ; se trata sobre todo de expresiones que son características de la lengua inglesa en América.

En este punto ya no hace falta comentario, pues el contenido de la definición es el mismo que en las otras comentadas del danés y del noruego.

El diccionario National encyklopedins ordbok (Bra Böcker, 1996: 27) dice que el concepto americanismo, que existe en el sueco desde 1875 , significa 'språkegenhet utmärkande för den nordamerikanska varianten av engelska', es decir, 'rasgo lingüístico del inglés norteamericano'. Y amerikanska quiere decir 'variant av engelska som talas i USA och Canada', o sea, 'variante del inglés hablado en los Estados Unidos y Canadá'.

Finalmente cabe mencionar dos diccionarios monolingües suecos, el Norstedts stora svenska ordbok (1995: 18) y el Norstedts plusordbok (1997: 22), cuyas acepciones/definiciones del término americanismo son análogas a la del diccionario National encyklopedins ordbok. Esto quiere decir que se relaciona el concepto con el inglés de los Estados Unidos y no con el español de Hispanoamérica.

Con respecto a la definición del concepto americanismo, pues, se puede afirmar que existen criterios de tratamiento homogéneos en las definiciones de los diferentes dicciona- 
rios monolingües ingleses y alemanes consultados. Esto quiere decir en concreto, como se ha señalado, que la mayoría de estos diccionarios coincide en el hecho de reflejar que el término se relaciona con el inglés americano. Y por otro lado, el artículo americanismo en los diccionarios monolingües escandinavos suele contener dos acepciones: en primer lugar relacionan el concepto con las lenguas autóctonas/no autóctonas de América y, en segundo lugar, con el inglés americano.

\section{El equivalente de americanismo en algunos diccionarios bilingües}

En las páginas anteriores hemos podido observar que no se define de modo igual el concepto de americanismo en los diccionarios monolingües hispánicos, en los románicos y en los germánicos; de ahí que nos haya parecido necesario examinar los diccionarios bilingües de las respectivas lenguas, para estudiar cómo son tratadas las equivalencias léxicas de un idioma a otro.

De hecho, lo que el usuario encuentra en los diccionarios bilingües es una falta de coherencia en las equivalencias, si se tiene presente, según lo expuesto aquí en las páginas anteriores, que americanismo - -en el caso de que sea el español la lengua de partida- no puede equivaler a Amerikanismus — para el alemán como lengua de destino--, y viceversa.

Vayamos por partes y empecemos con consultar los diccionarios bilingües de inglésespañol/español-inglés.

\subsection{Inglés -español/español-inglés}

Del diccionario inglés-español de Oxford (1994: 856) obtenemos la siguiente información:

Americanism a) (Ling) americanismo b) (characteristic) costumbre norteamericana, americanada c) (loyalty to America) americanismo.

Por lo ya estudiado y comentado, sabemos que americanism no equivale del todo al término español de americanismo. Si interpretamos este artículo lexicográfico atendiendo a nuestra conclusión expuesta en la sección anterior, la lectura de la definición podría formularse de la manera que sigue, con una fórmula que pone de manifiesto una evidente incoherencia:

\section{Cuadro 1}

(voz/giro del inglés americano $=$ ) Americanism $=$ americanismo ( $=$ voz/giro del español americano)

En efecto, el análisis anterior dio la conclusión de que americanism no equivalía a americanismo (nos referimos aquí a la primera acepción), es decir: 


\section{Cuadro 2}

\section{Americanism $\neq$ americanismo}

Lo que debemos preguntarnos llegados a este punto es si los lexicógrafos cometen el error de asumir y refrendar la idea de que entre estas dos unidades de las dos lenguas se puede realizar una equivalencia automática, o si se trata de una equivalencia "no del todo "exacta', pero "congruente" de los dos términos... O ¿acaso podemos hablar de "falsos amigos' en este caso? (Haensch, Ettinger y Werner, 1982: 522). En nuestra opinión, una definición por paráfrasis hubiera sido preferible a la opción por equivalencia, por cuanto hemos expuesto más arriba. En ese sentido, el siguiente ejemplo que aportamos supera parcialmente la incoherencia del anterior.

En realidad, la consulta al diccionario español-inglés de Oxford (1994: 39) muestra cómo americanismo es, en primer lugar, '(término estadounidense) Americanism', y en segundo lugar - y aquí sí se hace distinción entre la América Latina y la angloparlante'(-latinoamericano) Latin American word/expression'. La información de este artículo, pues, avala la idea de que americanismo puede equivaler tanto a hispanoamericanismo como angloamericanismo y lusoamericanismo, del modo que resumimos en la siguiente fórmula:

\section{Cuadro 3}

\section{lengua de origen: español}

$($ voz/giro del español americano $=)$ americanismo $=$

\section{lengua de destino: inglés}

americanism (angloamericanismo)

En América Latina no solamente se habla español, sino también portugués, así que conviene añadir lusoamericanismo a los términos de nuestra sinopsis, tal como hemos hecho en el cuadro 3 . Es necesario insistir en la necesidad de tener en cuenta el contexto de los elementos léxicos para la comprensión adecuada.

\subsection{Alemán-español/español-alemán}

En cuanto a los diccionarios bilingües del alemán-español/español-alemán el resultado de nuestro examen es similar a lo ya comentado sobre el inglés. En el diccionario Wörter- 
buch der spanischen und deutschen Sprache (Slabý, Grossmann e Illig, 1991: 37 y 75) se da la siguiente equivalencia del concepto:

Amerikanismus $m$ (Philol) americanismo $\mathrm{m} \|$ voz f americana.

cuya lectura es como sigue:

Cuadro 4

$($ voz/giro del inglés americano $=)$ Amerikanismus $=$ americanismo $(=$ voz/giro del español americano)

Sin embargo, la conclusión de nuestra investigación, basada en lo antes dicho, es que Amerikanismus no equivale a americanismo, tal como se expresa en el siguiente cuadro:

\section{Cuadro 5}

\section{Americanismus $\neq$ americanismo}

Conviene que citemos también la traducción inversa:

americanismo m Vorliebe f für das Amerikanische || nationalamerikanische Literaturströmung $\mathrm{f} \|$ am. Redewendung $\mathrm{f} \|$ Amerikanismus $\mathrm{m} \|$.

La primera acepción quiere decir 'preferencia por lo americano'. La segunda corresponde a 'corriente literaria nacional-americana', y la tercera se traduce por 'expresión americana'; para la última acepción se reserva la equivalencia a americanismo. El artículo informa, por lo tanto, entre otras cosas, de que al concepto español americanismo corresponde el equivalente Amerikanismus en el alemán.

En este mismo diccionario las unidades léxicas como americano y América se relacionan con los Estados Unidos. Habrá que consultar la entrada Südamerika y südamerikanisch para obtener el equivalente 'América del Sur' o 'sudamericano', es decir, para llegar a las voces que se relacionen con Hispanoamérica.

Por otro lado, en el Diccionario Avanzado Español-Alemán/Alemán-Español de Vox (1997) se da al concepto americanismo el equivalente 'Lateinamerikanismus', lo cual habrá de interpretarse en el sentido de 'rasgo lingüístico de las lenguas de origen latino en el continente americano', es decir, del francés, del español y del portugués. Si la lengua de partida es el alemán, aparece la equivalencia 'americanismo' para el término Amerikanismus. Y en el diccionario español-alemán de Langenscheidt (2002: 48) también se aprecia un cambio en la definición del término americanismo, pues ahora presenta la equivalencia con 'Amerikanismus' y con '(spanisch-) amerikanishcer Ausdruck', o sea, 'giro (español) americano'. Sin embargo, en la segunda parte de esta obra, alemán-español, (42) la definición del término Amerikanismus es 'americanismo'. 


\subsection{Danés-español/español-danés}

En los diccionarios de las lenguas escandinavas el resultado no es muy diferente a lo expuesto hasta ahora, pero vale la pena destacar que, cuando se toma el español como lengua de partida, aparece en la definición no sólo un equivalente sino también una definición por paráfrasis cuyo contenido es, en la mayoría de los casos, hispanoamericanismo. Reproducimos la definición encontrada al consultar un diccionario danés-español (Vater, 1993: 37, 2006: 40):

amerikanisme $-n,-r$ americanismo.

y la inversa, español-danés (Vater, 1993: 49, 2006: 56):

americanismo $m$ amerikanisme; [spansk-amerikansk sprogkendetegn el. -særpræg] Americanismo; [expresión característica del hispanoamericano]

Descubrimos la ausencia de coherencia, pues, entre la información recogida en un diccionario monolingüe danés donde se relaciona el término lingüístico sobre todo con los Estados Unidos y, por el otro, la información dada en un diccionario bilingüe. Por lo ahora expuesto llega el usuario a la conclusión de que americanismo es lo mismo que hispanoamericanismo, y ello a la vez que en un diccionario danés-inglés encuentra que es equivalente a angloamericanismo; lo cual, obviamente, puede causar una confusión ${ }^{5}$.

El término amerikaner se define como 'norteamericano de los Estados Unidos' y amerikansk '(norte)americano' mientras que americano se explica, en primer lugar, como 'amerikansk; sydamerikansk, spanskamerikansk' y, luego, como 'amerikaner', es decir 'americano, sudamericano, hispanoamericano' y 'norteamericano'. Se trata de definiciones que subrayan la antes mencionada incoherencia.

\subsection{Noruego-español/español-noruego}

A la misma conclusión se llega al estudiar un diccionario bilingüe noruego-español/español- noruego, ya que en el diccionario noruego-español (Blohm-Dal 1991: 4) se lee:

Amerikanisme americanismo.

y en el español-noruego (Loennecken, 1992: 27)

americanismo $m$ amerikanisme, amerikansk-spansk talemåte.

Americanismo, expresión hispanoamericana.

La consulta de una edición más reciente de un diccionario bilingüe noruego-español y español-noruego (Kunnskapsforlaget, 2005: 36, 5) muestra que americanismo se define como 
'amerikanism, amerikansk-spansk talemåte', o sea 'palabra americana o rasgo peculiar sobre todo del inglés americano' y 'frase o rasgo lingüístico del español de América'. Si la lengua de partida es el noruego sorprende que amerikanisme no aparece como entrada. Los términos amerikaner y amerikansk se definen como 'americano, norteamericano y estadounidense'.

\subsection{Sueco-español/español-sueco}

Por lo que se refiere al sueco, el diccionario sueco-español Svensk-spanskt lexikon (Cederholm et al.: 1989) da el "equivalente automático" en español, es decir que amerikanism equivale a americanismo; pero, cuando se toma el español como la lengua de partida, Spansk-svensk ordbok (Cederholm et al.: 1986), aparecen varias acepciones y explicaciones del término:

americanismo $m$ 1) spansk-amerikanskt ord el. uttryk, amerikanism

2) kännedom om Amerikas historia och amerikanska förhållanden

3) beundran för allt som kommer från Amerika [spec. fr. USA]

La primera acepción, y la que aquí nos interesa, nos informa de que el concepto significa 'voz o expresión hispanoamericana' y concluye ofreciendo el equivalente amerikanism, 'americanismo'.

Cuando consultamos el diccionario bilingüie español-sueco Norstedt (2003: 52) observamos que el término estudiado se define como:

americanismo $m \mathbf{1}$ amerikanism särdrag i amer. spanska $\mathbf{2}$ interesse för Amerika Americanismo $m 1$ rasgo caracteristico del español de América 2 interés por América

americanista es

person som studerar latinamerikansk historia och kultur persona que estudia la historia y la cultura latinoamericana

y el término americano se explica como:

I adj 1 sydamerikansk, från syd- eller Centralamerika 2 amerikansk från USA (Nordamerika) [...] 3 från amerikanska kontinenten [...]

1 sudamericano, de Sudamérica o Centroamérica 2 americano de los Estados Unidos (Norteamérica) [...] 3 del continente americano

Una vez más observamos que la explicación de los términos examinados no está en consonancia con las acepciones ya estudiadas. Ahora citemos la traducción inversa del mismo diccionario: 
En esta definición se explica que el equivalente dado, 'americanismo', contiene referencia al español de América. De nuevo nos encontramos con la ausencia de coherencia por un lado entre la definición del término en un diccionario monolingüe sueco y, por el otro, la de un diccionario bilingüe sueco-español. Así, el término se relaciona exclusivamente con el mundo hispanoamericano, hecho que da un resultado contrario a la acepción general de la voz en la comunidad lingüística sueca. Lo dicho resulta sorprendente cuando consultamos amerikansk y amerikanska, términos relacionados con los Estados Unidos y con el inglés americano (Norstedts, 2003: 10).

Para cerrar este apartado dedicado a la lexicografia bilingüe, podemos concluir que en los diccionarios de lenguas germánicas se suele dar el equivalente americanismo en la lengua de destino, que es el español. Por otro lado, cuando es el español la lengua de partida, suele proporcionarse, junto con el equivalente dado, alguna que otra explicación y en el artículo pueden aparecer hasta varias acepciones de las cuales por lo menos una relaciona el término con el español americano.

\section{Conclusión}

Los datos de la investigación que aquí hemos presentado permiten concluir que el uso, la definición, así como la comprensión del término americanismo resultan ser bastante distintos en los dos ámbitos lingüístico-culturales estudiados. La mayor divergencia se encuentra si se comparan los ámbitos inglés y alemán frente al mundo hispánico. En los diccionarios escandinavos el proceder lexicográfico parece más cauteloso, y se aportan las dos posibilidades de definición o equivalencia del concepto americanismo ('hispano' y 'anglo'), aunque se ponga más énfasis en la relación con el inglés americano; y lo mismo sucede en los diccionarios consultados de las lenguas románicas: el francés, el italiano y el portugués.

En nuestra opinión, la definición del concepto americanismo y su uso, tanto en el ámbito hispánico como en el germánico, es demasiado hispanocéntrica y anglocéntrica. Se suele olvidar que existen otras lenguas en América además del inglés y del español. Así que de hecho americanismo debería ser un hiperónimo para todas las lenguas habladas en dicho continente, es decir un hiperónimo de los hipónimos indoamericanismos, hispanoamericanismos, angloamericanismos, galoamericanismos, lusoamericanismos, etcétera. Al primer grupo/hipónimo mencionado pertenecerían voces o expresiones como náhuatlismos, quechuismos, algonquinismos, creeismos, iroquinismos, etcétera, es decir, los indoamericanismos prehispánicos, preanglosajones, etcétera. $\mathrm{Al}$ segundo pertenecerían los argentinismos, los mexicanismos, los chilenismos, etc. Al tercero, los canadiensismos y los estadounidensismos. Al último, los brasileñismos. Lo expuesto se sintetiza en el cuadro 6.

En realidad bien puede tratarse de un problema terminológico que fácilmente podría ser resuelto entre los lingüistas de los ámbitos en cuestión. Aparentemente hay algunos eruditos que se han dado cuenta de esta incoherencia terminológica, a juzgar, por ejemplo, por el título de un diccionario recientemente publicado, el Diccionario de hispanoamericanismos no recogidos por la Real Academia (Richard, 1998); pero por otro lado aparece el proyecto de la escuela de Augsburgo: Nuevo diccionario de americanismos, cuyo título es, en cambio, bastante ambigüo en nuestra opinión, y a la luz de lo que hemos expuesto en las páginas de este estudio. 


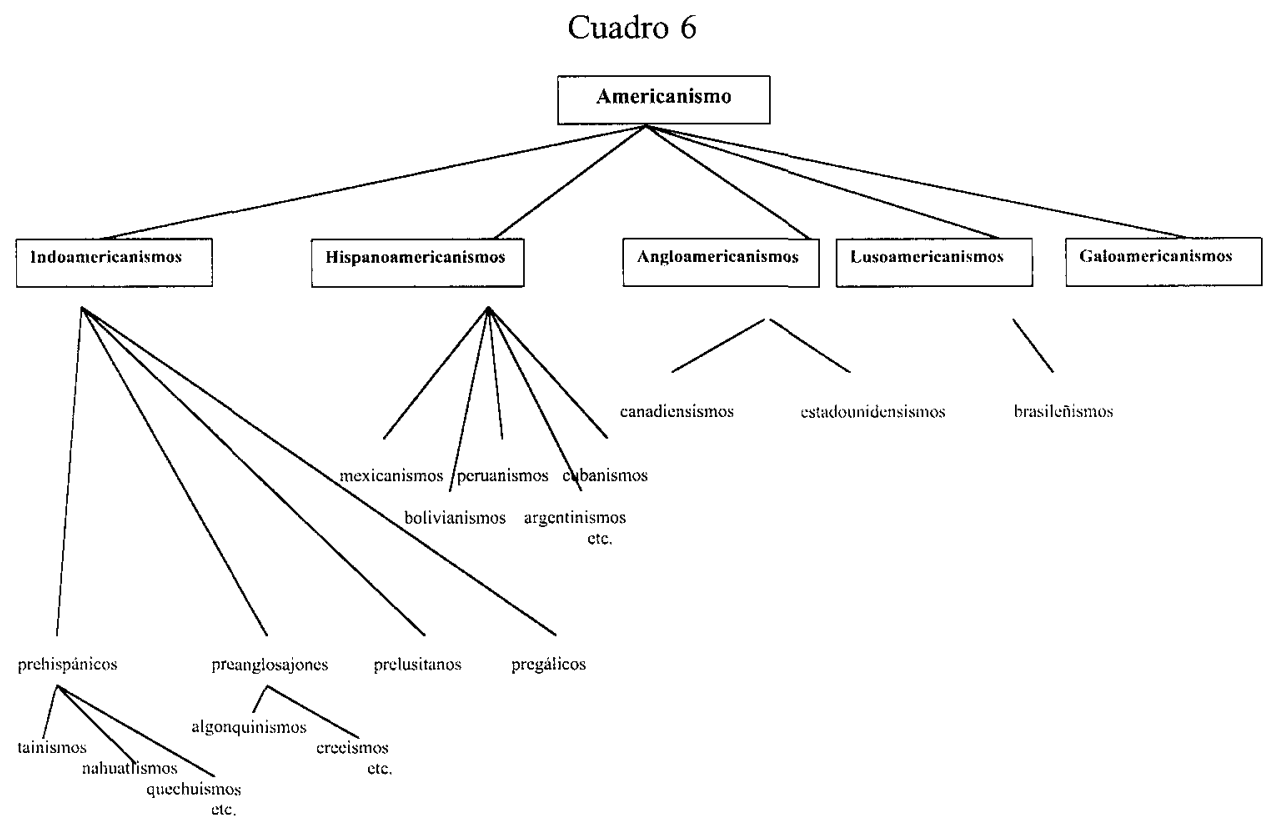

\section{Referencias bibliográficas}

Academia das Ciências de Lisboa (2001): Dicionário da Lingua Portuguesa Contemporânea. Lisboa, Verdo.

Albalá Hernández, P. (2000): Americanismos en las Indias del Poniente. Voces de origen indigena americano en las lengus del Pacifico. Frankfurt am Main/Madrid, Iberoamericana-Vervuert.

Alvar, M. (Dir.) (1996): Manual de dialectología hispánica. El español de América. Barcelona, Ariel.

Alvar, M. (1990): Americanismos en la "Historia" de Bernal Díaz del Castillo. Madrid, Ediciones de Cultura Hispánica.

Alvar Ezquerra, M. (1993): "La recepción de americanismos en los diccionarios generales de la lengua”. En Lexicografia descriptiva. Barcelona, Biblograf, págs. 343-351.

Alvarez-Prada, E. (2002): Langenscheidts Handwörterbuch Spanisch. Teil II Deutsch-Spanisch. Berlin, München, Wien, Zürich, New York, Langenscheidt.

Axelson, J. (ed.) (1986): The Standard Danish-English/English-Danish Dictionary. Copenhagen, Gyldendal.

Bajo Pérez, E. (1995): "Algunas notas sobre los tipos de americanismos y su destino en el español general". En La lengua española y su expansión en la época del Tratado de Tordesillas. Valladolid, Sociedad V Centenario, págs. 195-200.

Blom-Dahl, C.A. (1991): Norsk-Spansk blå ordbok. Oslo, Kunnskapsforlaget, Aschehoug-Gyldendal. Bra Böcker (1996): Nationalencyklopedins ordbok. Göteborg, Bra Böcker.

Bratli, C. (1947): Spansk-dansk ordbog. Copenhague, Fischers Forlag.

Brockhaus Wahrig (1980): Deutsches Wörterbuch, I. Wiesbaden/Stuttgart, Brockhaus Wahrig.

Brockhaus Wahrig (1986): Brockhaus Enzyklopädie. Mannheim, F.A. Brockhaus. 
Buesa Oliver, T. y J.M. Enguita Utrilla (1992): Léxico del español de América: su elemento patrimonial e indigena. Madrid, Ed. Mapfre.

Cândido de Figueiredo (1996): Grande Dicionário da Lingua Portuguesa. Lisboa, Bertrand Editora.

Casares, J. (1984): Diccionario ideológico de la lengua española. Barcelona.

Cederholm, B., et al. (eds.) (1986): Spansk-svensk ordbok. Stockholm, Natur och Kultur.

Cederholm, B., (ed.) (1989): Svensk-spanskt Lexikon. Stockholm, Natur och Kultur.

Clave (1996): Diccionario de uso del español acutal. Madrid, Ed. SM.

Collins (1994): English Dictionary. Glasgow Harper, CollinsPublishers.

De Mauro (2000): Il dizionario della lingua italiana. Milano, Paravia.

Det danske sprog- og litteraturselskab (1975): Ordbog over det danske sprog. Kóbenhavn, Gyldendal.

Det danske sprog- og litteraturselskab (1992-2000): Ordbog over det danske sprog. Supplementet.

Kóbenhavn, Gyldendal.

Duden (1989): Deutsches Universalwörterbuch. Mannheim, Leipzig, Wien, Zürich, Duden-Verlag.

Duden (1999): Das große Wörterbuch der deutsschen Sprache. Mannheim, Leipzig, Zürich, Dudenverlag.

Edda (2002): Íslensk orðabók. Reykjavík, Edda.

Enguita Utrilla, J.M. (1999): "Sobre la génesis de los americanismos léxicos". En Aleza Izquierdo, M. (ed.): Estudios de historia de la lengua española en América y España. Valencia, Universitat de València, págs. 57-69.

Espasa-Calpe (1958): Enciclopedia universal ilustrada, europea-americana. Madrid, Espasa-Calpe.

Frago García, J.A. (1999): Historia del español de América. Madrid, Gredos.

Friederici, G. (1960): Amerikanistisches Wörterbuch und Hilfswörterbuch für den Amerikanisten.

Hamburg, Cram, de Gruyter \& Co.

Gallimard (1992): Trésor de la langue française. París, Gallimard.

Garzanti (2000): I Grandi Dizionari Italiano. Italy, Garzanti.

Gútemberg Bohórquez, J. (1984): Concepto de 'americanismo' en la historia del español. Bogotá, Instituto Caro y Cuervo.

Gyldendal (2003): Den danske ordbog. Kóbehavn, Gyldendal.

Haensch, G. (1994): "Dos siglos de lexicografía del español de América: lo que se ha hecho y lo que queda por hacer”. En Wotjak, G. y K. Zimmermann (eds.), Unidad y variación léxicas del español de América. Frankfurt am Main, Vervuert, págs. 39-82.

Haensch, G. y R. Werner (eds.) (1993): Nuevo diccionario de americanismos, TT. Il, III. Santafé de Bogotá, Instituto Caro y Cuervo.

Haensch, G., Wolf, L., Ettinger, S. y R. Werner (1982): La lexicografia. De la lingüística teórica a la lexicografía práctica. Madrid, Gredos.

Haensch, G. (1982): "La lexicografia hispanoamericana entre la teoría y la práctica". Actas del primer Congreso Internacional sobre el español de América. Puerto Rico, págs. 555-577.

Haensch, G. (1978): "Un nuevo diccionario de americanismos: proyecto de la Universidad de Augsburgo", Thesaurus, XXXIII, págs. 1-40.

Istituto della Enciclopedia Italiana (1986): Vocabolario della Lingua Italiana. Roma, Istituto della Enciclopedia Italiana.

Kunnskapsforlaget (2005): Spansk blå ordbok. Spansk-norsk/norsk-spansk. Oslo, Kunnskapsforlaget. Langenscheidt (2002): Langenscheidts Handwörterbuch Spanisch. Berlin, München, Wien, New York, Langenscheidt.

Lapesa, R. (1981): Historia de la lengua española. Madrid, Gredos.

Lázaro Carreter, F. (1984): Diccionario de términos filológicos. Madrid, Gredos.

Loennecken, S. (1992): Spansk-Norsk ordbok. Oslo/Gjøvik, Kunnskapsforlaget, Aschehou-

Gyldendal. 
Lokotsch, K. (1926): Etymologisches Wörterbuch der amerikanischen (indianischen) Wörter im Deutschen. Heidelberg, Carl Winter's Universitätsbuchhandlung.

López Morales, H. (1998): La aventura del español en América. Madrid, Espasa Calpe.

Machado, J.P. (coord.) (1981): Grande Dicionário da Lingua Portuguesa. Lisboa, Amigos do Livro.

Malmberg, B. (1992): La América hispanohablante. Unidad y diferencia del castellano. Madrid, Istmo.

Mathews, M.M. (ed.) (1956): A Dictionary of Americanisms. On Historical Principles. Chicago, The University of Chicago Press.

Moliner, M. (1955-1967): Diccionario de uso del español. Madrid, Gredos.

Moliner, M. (1998): Diccionario de uso del español. Madrid. Gredos.

Morínigo, M.A. (1998): Nuevo diccionario de americanismos e indigenismos. Buenos Aires, Ed. Claridad.

Morínigo, M.A. (1996): Diccionario del español de América. Madrid, Anaya y Mario Muchnik.

Morínigo, M.A. (1993): Diccionario del español de América. Madrid, Anaya.

Müller, G. y G. Heinz (2001): Langenscheidts Handwörterbuch Spanisch. Teil I Spanisch-Deutsch. Berlin, München, Wien, Zürich, New York, Langenscheidt.

Natur och kultur (1986): Spansk-svensk ordbok. Stockholm, Natur och kultur.

Norske samlaget, Det (2001): Nynorskordboka. Definisjons- og rettskrivingsordbok. Oslo, Det norske samlaget.

Norske samlaget, Det (1966): Norsk ordbok. Ordbok over det norske folkemålet og det nynorske skriftmalet. Oslo, Det norske samlaget.

Norstedts (1995): Norstedts stora svenska ordbok. Göteborg, Norstedts.

Norstedts (1997): Norstedts plusordbok. Göteborg, Norstedts.

Nova Fronteira (1975): Novo Dicionário da lingua portuguesa. Rio de Janeiro, Ed. Nova Fronteira.

Oxford (1989): The Oxford English Dictionary. Oxford, Clarendon Press.

Oxford (1994): The Oxford Spanish Dictionary, Spanish-English/English-Spanish. Oxford, New York, Madrid, Oxford University Press.

Palmer, Ph. M. (1933): Der Einfluss der Neuen Welt auf den deutschen Wortschatz 1492-1800. Heidelberg, Carl Winter's Universitätsbuchhandlung.

Palmer, Ph. M. (1939): Neuweltwörter im Deutschen. Heidelberg, Carl Winter's Universitätsbuchhan dlung.

Politikens forlag (1986): Nudansk ordbog. Kóbenhavn, Politikens forlag.

Politikens forlag (2000): Nudansk ordbog med etymologi. Kóbenhavn, Politikens forlag.

Porto Ed. (1977): Dicionário da Lingua Portuguesa. Porto Ed., Porto.

Pottier-Navarro, H. (1992): "El concepto de Americanismo léxico", RFE LXXII, págs. 297-312.

Random House (1983): The Random House Dictionary of the English Language. New York, Random House.

Real Academia Española (1992): Diccionario de la lengua española. Madrid, Espasa-Calpe.

Real Academia Española (2001): Diccionario de la lengua española. Madrid, Espasa-Calpe.

Richardo, R. (1998): Diccionario de hispanoamericanismos. Madrid, Cátedra.

Riquelme, J. (1998): Los anglicismos. Anglismos y anglicismos: huéspedes de la lengua. Alicante, Ed. Aguaclara.

Robert (1992): Dictionnaire historique de la langue française. París, Le Robert.

Robert (1998): Dictionnaire historique de la langue française. París, Le Robert.

Robert (2001): Le Grand Robert de la langue française. Paris, Le Robert.

Rona, J.P. (1969): “QQué es un americanismo?” Simposio de México, enero 1968. Actas, informes y comunicaciones. México, UNAM.

Salamanca (1996): Diccionario de la lengua española. Madrid, Santillana y la Universidad de Salamanca. 
Shaw Fairman, P. (1988): "La huella española en la lengua inglesa: comercio, colonización cultura", Archivum, 37-38, págs. 305-327.

Slabý, R.J., Grossmann, R. y R. Illig (1991): Wörterbuch der spanischen und deutschen Sprache. Barcelona, Herder.

Steel, B. (1990): Diccionario de americanismos. Madrid, SGEL.

Steel, B. (1999): Breve diccionario ejemplificado de americanismos. Madrid, Arco/Libros.

Svenska akademien (1898): Svenska Akademiens Ordbok över Svenska Språket. Stockholm.

Svenska akademien: Svenska Akademiens Ordbok över Svenska Språket. <http://www.g3.spraakdata. gu.se/saob> (15.01.2007).

Sörensen, S. (1999): Ensk-islensk orðabók með alfrceðilegu ivafi. Reykjavík, Mál og menning.

Torres Torres, A. (2002): "Criollización del español y americanismos léxicos". En Espaeza Torres, M.A., Fernández Salgado, S. y H.-J. Niederehe (eds.): Actas del III Congreso Internacional de la Sociedad Española de Historiografia Lingüistica Vigo, 7-10 de febrero de 2001. Hamburg, Helmut Buske Verlag.

Universitetsforlaget (1997): Bokmålsordboka. Oslo, Universitetsforlaget.

Vaquero de Ramírez, M. (1996): El español de América II. Morfosintaxis y léxico. Madrid, Arco/ Libros.

Vater, P. (1993): Spansk-Dansk Ordbog. Kóbenhavn, Gyldendal.

Vater, P. (1994): Dansk-Spansk Ordbog. Kóbenhavn, Gyldendal.

Vox (1995): Diccionario general ilustrado de la lengua española. Barcelona, Biblograf.

Vox (1997): Diccionario Avanzado (Español-Alemán/Alemán-español). Stuttgart, Ernst Klett Verlag.

Wahrig, G. (1986): Deutsches Wörterbuch. München, Mosaik Verlag.

Websters (1961): Websters Third New Dictionary of the English Language, Springfield, Massachusetts, Merriam-Webster Inc.

Werner, R. (1994): “¿Qué es un diccionario de americanismos?”. En Wotjak, G. y K. Zimmermann (eds.): Unidad y variación léxicas del español de América. Frankfurt am Main, Vervuert, págs. 9-38.

Werner, R. (1978): "Zur Lexicographie des amerikanischen Spanisch. Vorschläge für ein neues Amerikanismen-Wörterbuch". En Haensch, G. y R. Werner (eds.), Referate der I. wissenschaftlichen Tagung des Deutschen Hispaninstenverbands Augsburg 25.-26.2.1977. Augsburg, págs. 132-157. Wotjak, G. y K. Zimmermann (eds.) (1994): Unidad y variación léxicas del español de América. Frankfurt am Main, Vervuert.

Zamora Munné, J.C. y J.M. Guitart (1988): Dialectología Hispanoamericana. Teoria, descripción, historia. Salamanca, Ed. Almar.

Zamora Vicente, A. (1979): Dialectología española. Madrid, Gredos.

Zingarelli, N. (2002): Vocabulario della lingua italiana. Bologna, Zanichelli. 